\title{
Global facial rejuvenation, new technique
}

\author{
Giuseppe Colombo, Vittorio Ruvolo \\ Koru Day Clinic Center, Via Paleocopa 5/3, Savona 17100, Italy \\ Correspondence to: Dr. Giuseppe Colombo, Koru Day Clinic Center, Via Paleocopa 5/3, Savona 17100, Italy. \\ E-mail: info@aesthetic-koru.it
}

How to cite this article: Colombo G, Ruvolo V. Global facial rejuvenation, new technique. Plast Aesthet Res 2018;5:25. http://dx.doi.org/10.20517/2347-9264.2018.29

Received: 20 Apr 2018 First Decision: 19 Jun 2018 Revised: 9 Jul 2018 Accepted: 12 Jul 2018 Published: 30 Jul 2018

Science Editor: Raffaele Rauso Copy Editor: Jun-Yao Li Production Editor: Huan-Liang Wu

\begin{abstract}
Facial aging is the combination of multiple effects such as sun exposure, tobacco, environmental stress and smog, reflecting the cumulative and dynamic effects of time on the skin, soft tissues and the deep structural components of the face that show an important change structural features of the skin and loss of facial volume. There are many different techniques currently used to perform face lifting, the ultimate goal is to get good results with respect for patient safety. This article describes a new approach to facial rejuvenation combining superficial musculoaponeurotic system (SMAS) plication elements on four vectors, with a blepharoplasty to achieve a lasting improvement in facial aging. The plication of the SMAS on the suture provides three vectors of elevation under the skin in the middle rhytidectomy, linked to the Lorè fascia and to the third platys elevation vector behind the ear. The blepharoplasty technique is often unavoidable in the execution of the global facial rejuvenation. This allows obtaining excellent results both in terms of aesthetic and of a good patient empowerment. This new surgical technique, called "KORU technique", was used on 31 patients between October 2010 and October 2012, producing lasting results, reducing injuries and respecting anatomical planes. This approach can be safely and easily performed under local anesthesia as an isolated midface procedure, respecting and safeguarding the facial nerve. This type of chiropractic technique can be used by young surgeons.
\end{abstract}

Keywords: Facial aging, rejuvenation, smas, surgical technique, anatomical planes, midface, blepharoplastry

\section{INTRODUCTION}

The aging of the face can produce the following effects: elongation of the lower eyelid, flattery of the malignant eminences, volumetric loss in the undersea area of the cheek, prominence of the cheeks and deepening of the nasolabial fold. The facial support ligaments support the soft tissue of the face in a normal ana-

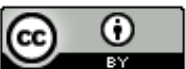

(C) The Author(s) 2018. Open Access This article is licensed under a Creative Commons Attribution 4.0 International License (https://creativecommons.org/licenses/by/4.0/), which permits unrestricted use, sharing, adaptation, distribution and reproduction in any medium or format, for any purpose, even commercially, as long as you give appropriate credit to the original author(s) and the source, provide a link to the Creative Commons license, and indicate if changes were made.

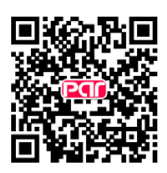


tomical position, resisting the gravitational change. In 1976, Mitz and Peyronie ${ }^{[1]}$ described the superficial musculoaponeurotic system (SMAS) and after this date multiple surgical procedures were improved. These techniques produce excellent results, but require a thorough dissection and have the potential for greater morbidity. The anatomical distribution of the facial nerve has been studied by various authors ${ }^{[2]}$ and during the surgical dissection the most dangerous area of the face, the most worried one, must be considered. The frontal branch is one of the most commonly damaged nerves in plastic surgery. The path of the frontal branch can be drawn on the skin by two divergent lines that start from the region of the earlobe and go ${ }^{[3]}$ to the lateral extremity of the eyebrow ${ }^{[4]}$ and to the highest front fold. To locate the frontal branches it is useful to look for the superficial temporal artery. The branches of the buccal and zygomatic nerve have a deep position and in the nasolabial fold there is an excess of skin and fat which provides greater protection to the underlying nerve. The mandibular branch ${ }^{[5]}$ is located above the lower margin of the mandible in $80 \%$ of the cases, in the remaining $20 \%$ it forms an arch under the lower edge of this bone and always flows inside or in depth of the muscle fibers of the platysma so in this area there is almost no danger of injuring the nerve. In this study, the authors, Colombo and Ruvolo, describe a new simple and safe face lifting technique, the KORU technique, designed for their patients and to guide the young surgeons in a first approach to this surgical procedure.

\section{METHODS}

Between October 2010 and October 2012, 31 patients were operated using the facial lifting surgical technique, called KOru, conceived by the authors Colombo and Ruvolo. There were 25 women and 6 men. The age of the patients ranged between 35 and 64 years. All patients underwent the primary facelift.

\section{TECHNICAL DESCRIPTION}

The skin incision is performed along the temporal hairline and extends into the conventional position of the facelift in the postural auricular groove, posteriorly extending on the mastoid following an external auditory canal line. The skin flap is elevated in a subcutaneous plane and the dissection extends up to $2 \mathrm{~cm}$ from the labial commissure to respect the buccal branches of the facial nerve. Inferiorly the dissection is carried out to expose the neck and the mandibular edge, externally extending up to the orbital edge and beyond the upper edge of the zygoma. The authors suggest that the dissection is safer and it's less difficult to find the right dissection plan if the surgeon started from the temporal region. All face-lift procedures were associated with a blepharoplasty using the technique of Adamson et al ${ }^{[6]}$ and Mendelson ${ }^{[7]}$. The SMAS plications are performed on four vectors: the first vector passes from the external cantus to the tragus and gives a vertical direction; the second vector goes from Darwin to the tragus and gives a vertical/oblique direction; the third vector goes from the angle of the jaw to the Lore band; the fourth vector that goes from the back/subauric platisma to the mastoid. The last two vectors give a vertical direction and an angle definition of the jaw that draws a $U$ around the earlobe [Figures 1-3].

The choice of these traction points was according to the area of the face where the branches of the facial nerve are deeper to work safely. A plication suture performed between cantus and tragus was made to create a spindle to restore the cheek volume [Figure 4]. The suture [Figures 5 and 6] takes less tissue on the marginal area in the direction of cantus and tragus and takes more tissue in the central zone of placation, in this way the author restores the loss of volume at a point of greater projection of the face and gives an all-round look 3D topography that is delineated by series of arcs and convexities ${ }^{[8-18]}$ [Figure 2].

\section{RESULTS}

The authors performed 31 interventions, using the KORU technique, from October 2010 to October 2012. In no case there were infections, there was minimal tension on the suture line. There is minimal postoperative 


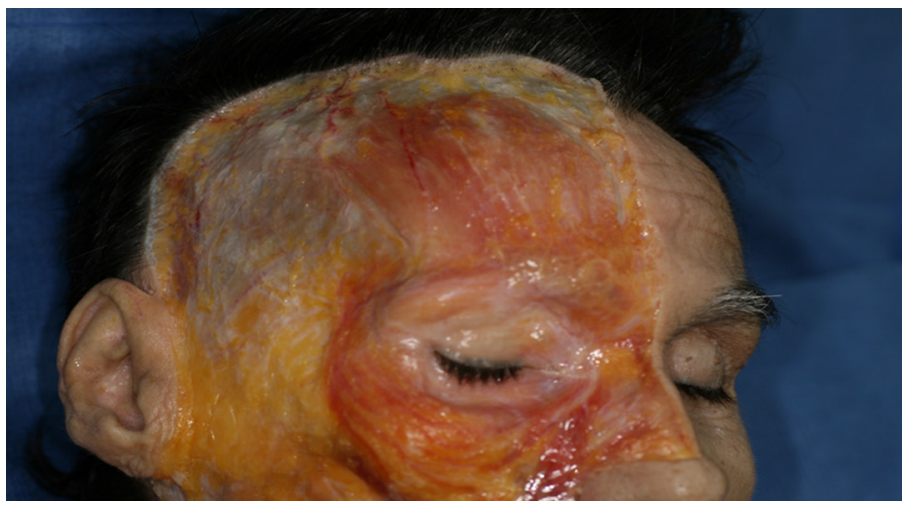

Figure 1. Temporoparietal fascial

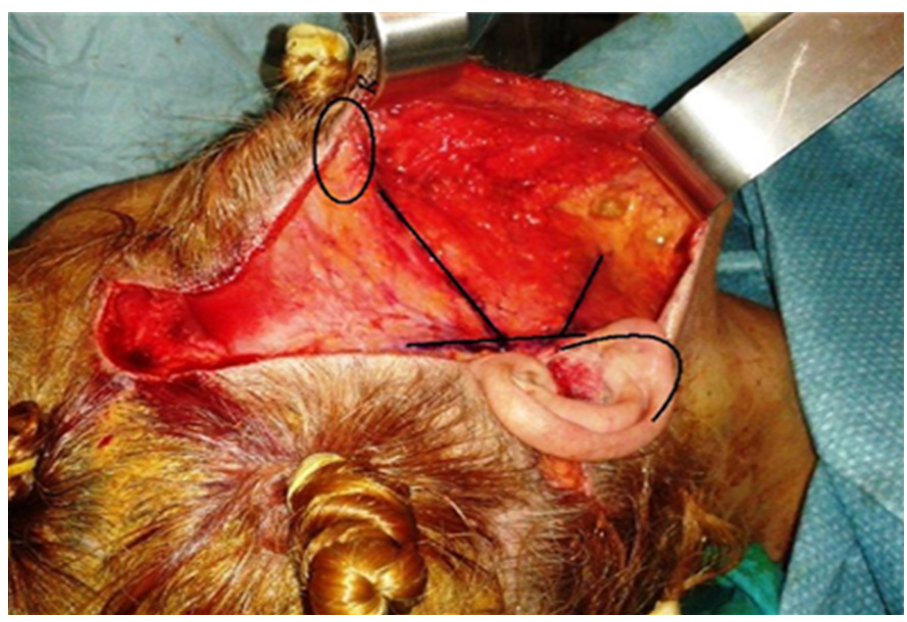

Figure 2. Traction points

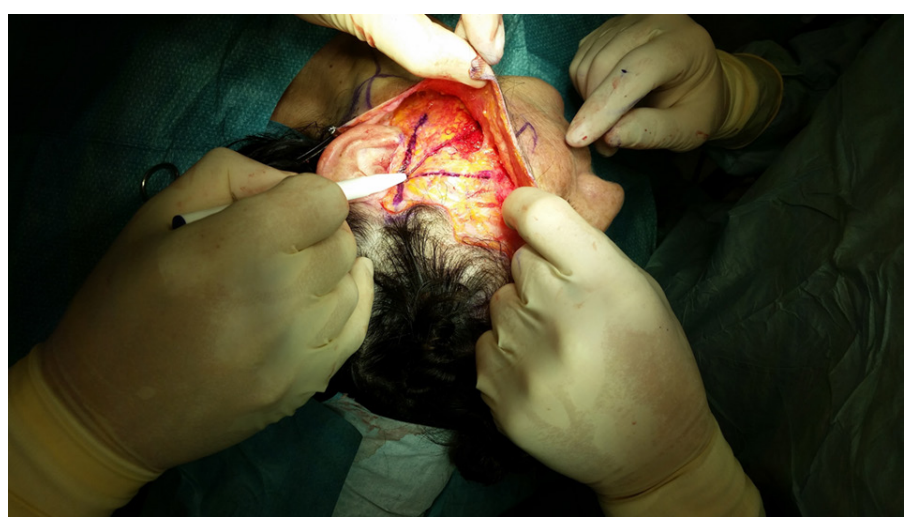

Figure 3. Superficial musculoaponeurotic system

edema, as well as minimal postoperative bruising. This technique produces effective results, supports a volume of midface without causing injury to the facial nerve. This study showed a new, safe approach to facial rejuvenation combining the elements of the SMAS placenta with a blepharoplasty to achieve long-term improvement of middle-aged aging and a more natural effect. The low incidence of morbidity was accompanied by rapid convalescence and most patients were able to return to work and social activities very early with 


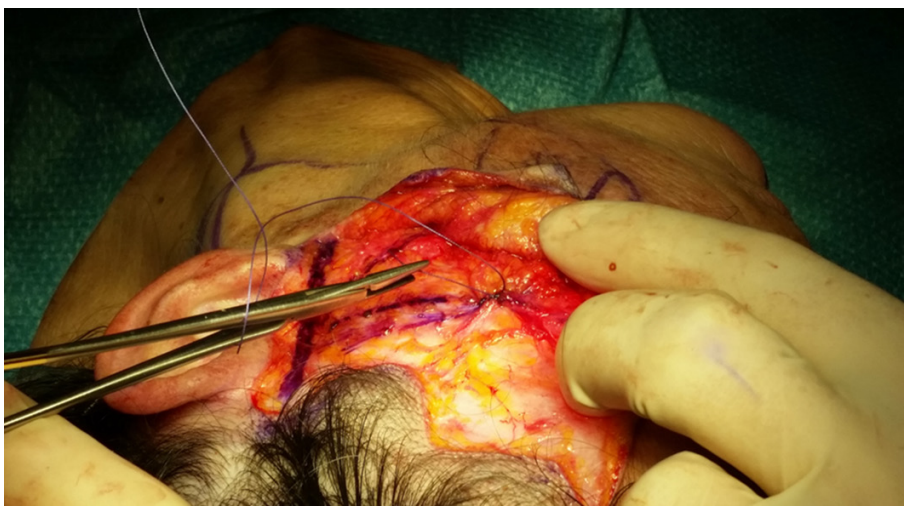

Figure 4. Emplicature superficial musculoaponeurotic system

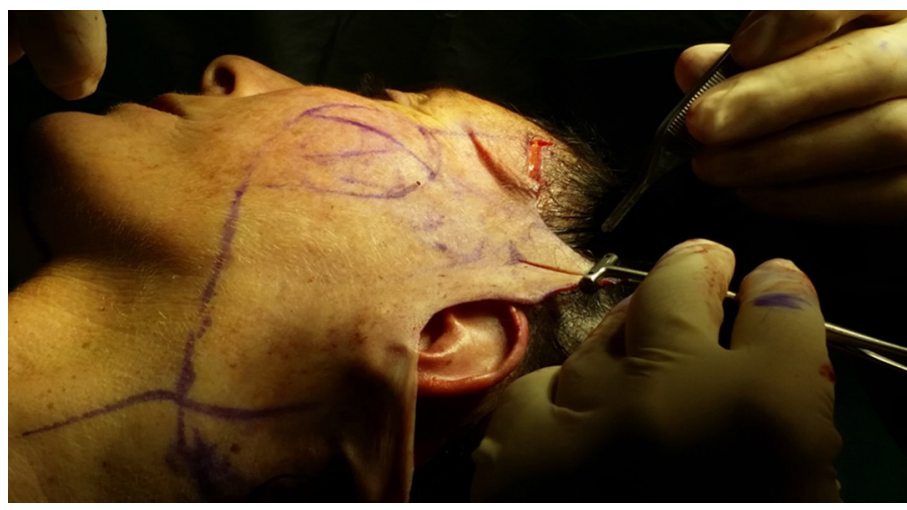

Figure 5. Cute positioning for sutures

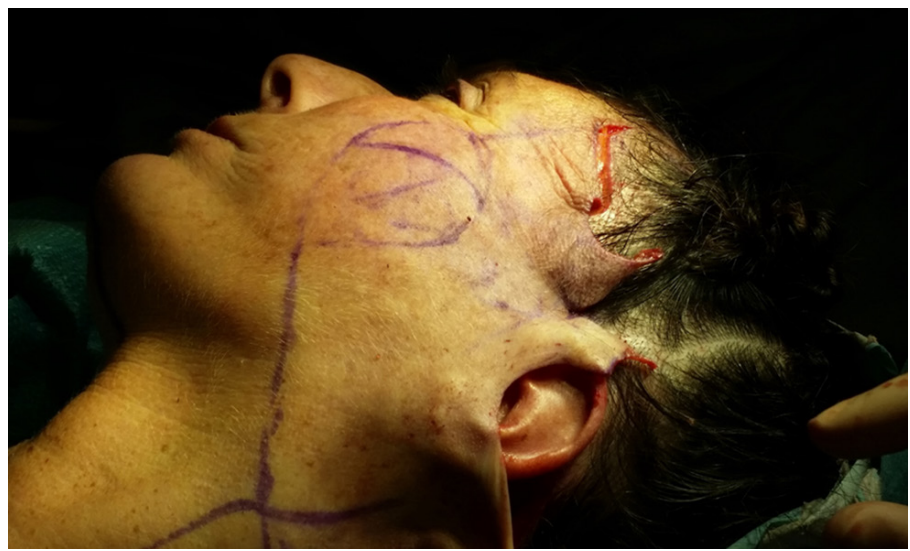

Figure 6. Cut of the skin flaps on the delimeted line

excellent satisfaction.

After a follow-up of the treated patients, the authors saw that there were no errors, but experiences described by the patients related to the feeling of tension in the tissue fixation points.

Like all the techniques, at the beginning the authors had slightly longer intervention times than traditional techniques, but the results were excellent. 
During the execution of this new technique there were no errors with important post-operative aesthetic consequences.

There were initial difficulties in finding the plans despite the reference points mentioned above.

\section{DISCUSSION}

After the description of SMAS in $1976^{[1]}$, surgical attempts to correct aging were directed towards stiffening techniques of SMAS. The introduction of Hamra ${ }^{[19]}$ of deep-plane rhytidectomy in 1990 focused attention on a completely new concept of rejuvenation through the composite repositioning of facial tissues. The peripheral anatomy of the facial nerve has been intensively studied by various authors; they analyzed the anatomical distribution of the branches and the different types of nerve connections that exist between them. This document describes a new safe lifting technique that preserves the facial nerve and may be easier. This procedure has opened up the chances of further morbidity in lifting the median face. The dissection of the skin flap initiated with temporal region incision, the SMAS placation was performed by three sutures describing three vectors. The superior suture that goes from the external cantus to the tragus is made to produce an even more sickly increase. While the platysma suture on the mastioid minimizes tension on the suture line. The authors, Colombo and Ruvolo, always associate SMAS plication with Adamson blepharoplasty and a fat sliding on Mendelson. An additional technique is performed for blepharoplasty with a lower lid. This operative procedure uses the principle of anchoring the upper edge of the lower lid by suturing a triangular flap of the muscle from it to the upper lateral part of the orbital rim. This more effective support for the lower edge of the lid allows the redundant fabric to be removed without obtaining an ectropion ${ }^{[20]}$. The concept of replacing the protruding fat of the lower lid in the orbit and keeping it there by strengthening the orbital septum is tempting because it embodies the goal of cosmetic surgery to restore the juvenile ideal by reversing the structural changes of aging. This concept is in contrast to that of standard blepharoplasty procedures that use a simple excision and narrowing approach to obtain a superfcial improvement. Based on their experience, the authors believe that SMAS plication and SMAS staining provide similar results 5-10, so they only choose the blepharoplasty plication procedure, obtaining the important result as an excellent aesthetic result with a high level of patient satisfaction. The KORU face lifting technique that affects the central area, the orbital area and the neck gives a global refreshing appearance to the face, giving a natural look.

This new technique is a possibility to replace the face-lift.

\section{DECLARATIONS}

\section{Authors' contributions}

Concept and design: Colombo G, Ruvolo V

Manuscript preparation: Colombo G, Ruvolo V

Critical revision and finalizing of the manuscript: Colombo G, Ruvolo V

\section{Availability of data and materials}

The data were strictly obtained from medical records according to the privacy policy and ethics code of our institute.

\section{Financial support and sponsorship}

None.

\section{Conflicts of interest}

Both authors declared that there are no conflicts of interest. 


\section{Ethical approval and consent to participate}

The study is approved and patients have agreed to partecipate

\section{Consent for publication}

The patients gave their consent to the use of the photos shown in the article

\section{Copyright}

(c) The Author(s) 2018.

\section{REFERENCES}

1. Mitz N, Peyronie M. The superficial muscoloaponeurotic system (SMAS) in the parotid and cheek area. Plast Reconstr Surg 1976;58:80-8.

2. Correia P, Zani R. Surgical anatomy of the facial nerve, as related to ancillary operations in rhytidoplasty. Plast Reconstr Surg 1973;52:54952.

3. Baket TJ, Gordon H. Complications of rithidectomy. Plast Reconstr Surg 1967;40:31.

4. Byars IT. Preservation of the facial nerve in operations for benign conditions of the parotid area. Ann Surg 1952;136:412.

5. Nelson DW, Gingrass RP. Anatomy of the mandibular branches of the facial nerve. Plast Reconstr Surg 1979;64:479-82.

6. Adamson JE, McCraw JB, Carraway JH. Use of a muscle flap in lower blepharoplasty. Plast Reconstr Surg 1979;63:359-63.

7. Mendelson BC. Fat preservation technique of lower-lid blepharoplasty. Aesthetic Surg J 2001;21:450-9.

8. Coleman SR, Grover R. The anatomy of the aging face: volume loss and changes in 3-dimensional topography. Aesthet Surg J 2006;26:S49.

9. Wilhelmi BJ, Mowlavi A, Neumeister MW. The safe face lift with bony anatomic landmarks to elevate the SMAS. Plast Reconstr Surg 2003;111:1723-6.

10. Mentz HA 3rd, Ruiz-Razura A, Patronella CK, Newall G. Facelift: measurement of superficial muscular aponeurotic system advancement with and without zygomaticus major muscle release. Aesthetic Plast Surg 2005;29:353-62.

11. Baker TJ, Stuzin JM. Personal technique of face lifting. Plast Reconstr Surg 1997;100:502-8.

12. Kamer FM, FrankelAS. SMAS rhytidectomy versus deep plane rhytidectomy: an objective comparison. Plast Reconstr Surg 1998;102:87881.

13. Ruess W, Owsley JQ. The anatomy of the skin and fascial layers of the face in aesthetic surgery. Clin Plast Surg 1987;14:677-82.

14. Massiha H. Short-scar face lift with extended SMAS platysma dissection and lifting and limited skin undermining. Plast Reconstr Surg 2003;112:663-9.

15. Rohrich RJ, Pessa JE. The fat compartments of the face: anatomy and clinical implications for cosmetic surgery. Plast Reconstr Surg 2007;119:2219-27.

16. Özdemir R, Kilinç H, Ünlü RE, Uysal AÇ, Sensöz O, Baran CN. Anatomicohistologic study of the retaining ligaments of the face and use in face lift: retaining ligament correction and SMAS plication. Plast Reconstr Surg 2002;110:1134-47.

17. Webster RC, Smith RC, Papsidero MJ, Karolow WW, Smith KF. Comparison of SMAS plication with SMAS imbrication in face lifting. Laryngoscope 1982;92:901-12.

18. Little JW. Volumetric perceptions in midfacial aging with altered priorities for rejuvenation. Plast Reconstr Surg 2000;105:252-66.

19. Hamra ST. The deep plane rhytidectomies. Plast Reconstr Surg 1990;86:53

20. Adamson JE, McCraw JB, Carraway JH. Use of a muscle flap in lower blepharoplasty. Plast Reconstr Surg 1979;63:359-63. 